\title{
EDITORIAL
}

\section{Recent Advances in the Field of Metal Based Drugs: from Structural Studies, Towards Biological Properties, and Innovative Strategies for Drug Delivery}

A question that probably comes from the readers is: "why is an issue titled "Recent advances in the field of metal based drugs: from structural studies, towards biological properties, and innovative strategies for drug delivery" published in a crystallography journal such as TOCryJ?"”

The rationale is that a deep knowledge of crystal and molecular structures is fundamental for the development of metal based drugs, for understanding their mechanism of action and for designing suitable materials for efficiently administering the drugs themselves. X-ray crystallography represents the main way for gathering accurate structural information. Thus, inviting authors, reviewers, editors and publishers to take care of the enormous pool of information that can be obtained from X-ray structures is a duty that crystallography oriented journals should cultivate with tireless efforts.

It is well known that metal compounds have a significant impact on the health of humans and domestic animals [1-4]. Once synthesis, structural and chemical characterization of potential drugs have been performed, subsequent steps consist in evaluating biological activity (cytotoxicity, oxygen radical scavenging, etc., in vitro and in animals), and in optimizing the administration strategies. Although the evaluation of bio-activity may refer to reliable and well known standard protocols and regulations, that are available from public institutions, the search for drug administration ways aimed to improve curative effects and reduce undesired side effects is still quite a new field that deserves intensive efforts [5-7]. This TOCryJ issue was thought as a contribution to the field of metal based drugs, starting from the solid state structure of selected compounds, passing through the evaluation of biological activities, then touching the field of design and performance of suitable materials for drug loading and drug delivery.

Three types of compounds have been selected and reviewed through the papers titled:

1. Thiosemicarbazone and their metal complexes: from structure to activity.

2. Dinuclear gold(III) complexes as potential anticancer agents. Structure, reactivity and biological profile of a series of gold(III) oxo-bridged derivatives.

3. Metal compounds that contain non-steroidal anti-inflammatory drugs from the oxicam family. Structure, biological activity and strategies for administration.

Titles 1 and 3 were chosen because they present metal compounds that contain bio-active molecules as ligands. Title 2 was selected because it is representative of a way for evaluating a new class of compounds that contain bio-active molecules per se, the ligands being innocent species.

As regards thiosemicarbazones and their metal derivatives, Giorgio Pelosi grouped the compounds on the basis of: cytotoxic, anti-protozoal, and anti-bacterial and anti-viral activities. Important inferences between the structural studies and certain biological activities could be found. The more reasonable explanation for the higher activity by the metal-thiosemicarbazone complexes when compared to free ligands passes through the prevalence of the diffusive mechanism over the active transport mechanism across the membranes. The chelation of the metal ion by the most polar regions of the ligands (the donor atoms) allows an easier uptake by the cell. The X-ray diffraction studies confirm that the complex molecules have many more hydrophobic exterior regions than the ligands. The results from X-ray structural determinations are also very important to ascertain whether bidentate or tridentate chelation by thiosemicarbazones occurs. The tridentate coordination mode often corresponds to more inert species for first raw transition metal ions. Of course, factors other than structural ones are important for activity and selectivity. For example, the redox properties of ligand and complex molecules are often important in this sense.

The review by Luigi Messori et al., is an example for designing and performing the synthesis, the chemical and structural characterization, the evaluation of biological properties and the drawings of perspectives for their future use as drugs. The field is that of novel cytotoxic non-platinum substances, namely gold(III) compounds based on the dinuclear $\mathrm{Au}_{2} \mathrm{O}_{2}$ core, thought of as possible anti-cancer drugs. The strategy for building poly-nuclear platinum derivatives produced promising results and was recently extended to ruthenium compounds. A series of $\left[\left(\mathrm{bipy}^{\mathrm{nR}}\right) \mathrm{Au}(\mu-\mathrm{O})_{2}\left(\mathrm{bipy}^{\mathrm{nR}}\right)\right]\left[\mathrm{PF}_{6}\right]_{2}$ named Auoxos were designed after that efficacious cytotoxic activities were revealed by several other $\mathrm{Au}(\mathrm{III})$ complexes. The new Auoxos compounds are characterized by an appreciable solubility and stability in physiological media. Furthermore, their anti-proliferative activity in vitro is promising when compared to cisplatin. Note worthy, one of the compounds, namely Auoxo6, is ca five times more active than cisplatin for certain cancer cell types. Analyses aimed to gain specific mechanistic information on the complexes 
showed that Auoxo6 has striking similarities to histone deacetylase inhibitors. On another side, there are evidences that Auoxos act as precursors for $\mathrm{Au}(\mathrm{I})$ species.

The review by Gabriella Tamasi deals with metal-complexes that contain widely used anti-inflammatory anti-rheumatic drugs. It emphasizes the vision that prompted the works on this type of complexes: i.e. the combination of pharmaceutical compounds with properly selected metal cations may bring about synergic effects from the components after dissociation of coordination linkages occurred. Thus, a single coordination molecule may have a multi-therapeutic action particularly sought for complicate pathologies like cancer, inflammation and auto-immune diseases. Copper(II)-oxicam complexes are expected to play antiinflammatory effects by oxicam drugs (acting via cyclo-oxygenase inhibition), reinforced by the oxygen radical scavenging activity by $\mathrm{Cu}^{\mathrm{II}}$ center. Tin(IV)- and $\mathrm{P}^{\mathrm{II}}$-oxicam complexes were selected because of the possible combined effects against inflammation (from oxicam) and cancer (from coordination residues). The review reports also on materials planned for drug delivery. In particular, swellable hydrogels that contain histidine residues resulted suitable to be loaded by $\mathrm{Cu}^{\mathrm{II}}$-oxicam compounds. The hydrogels are sensitive to temperature, $\mathrm{pH}$, ionic strength, as regards their swelling and releasing properties. Note worthy, the key aspects for rationalizing bio-activity and gel-metal compound interactions are the crystal and molecular structures.

In conclusion all the three papers stress the importance of molecular structures and of intermolecular and packing interactions in works on metal based drugs. Through these information, inferences on bio-activity and design of carrier materials can be drawn. It is advisable that studies on materials able to carry/deliver drugs more and more accompany works devoted to synthesis, chemical and biological characterization.

\section{REFERENCES}

[1] Palmer AE, Franz KJ. Cellular metal homeostasis and trafficking. Chem Rev 2009; 10: $4533-5$.

[2] Gielen M, Tiekink ERT. Eds. Metallotherapeutic drugs and metal-based diagnostic agents. The use of metals in medicine. New Jersey, USA: John Wiley \& Sons Inc 2005.

[3] Orvig C, Abrams MJ. Medicinal inorganic chemistry: introduction. Chem Rev 1999; 2201-4.

[4] Farrell NP. Ed. Uses of inorganic chemistry in medicine. Cambridge, UK: The Royal Society of Chemistry 1999.

[5] Krause-Heuer AM, Grant MP, Orkey N, Aldrich-Wright JR. Drug delivery devices and targeting agents for Platinum(II) anticancer complexes. Aust J Chem 2008; 61: 675-81.

[6] Casolaro M, Cini R, Del Bello B, Ferrali M, Maellaro E. Cisplatin/hydrogel complex in cancer therapy. Biomacromolecules 2009; 10: 944-9.

[7] Wieder ME, Hone DC, Cook MJ, Hendsley MM, Gavrilovic J, Russell DA. Intracellular phodynamic therapy with photosensitizer-nanoparticle conjugates: cancer therapy using a 'Trojan horse'. Photochem Photobiol Sci 2006; 5: 727-35.

(C) Renzo Cini; Licensee Bentham Open.

This is an open access article licensed under the terms of the Creative Commons Attribution Non-Commercial License (http://creativecommons.org/licenses/bync/3.0/) which permits unrestricted, non-commercial use, distribution and reproduction in any medium, provided the work is properly cited.

Renzo Cini Guest Editor

Department of Chemistry University of Siena, Via Aldo Moro 2, I-53100 Siena

Italy

Tel: ++390577234368

Fax: ++390577234254

E-mail: cini@unisi.it 